\title{
Decoding the usefulness of non-coding RNAs as breast cancer markers
}

\author{
Maria Amorim ${ }^{1,2}$, Sofia Salta ${ }^{1,2}$, Rui Henrique ${ }^{1,3,4}$ and Carmen Jerónimo ${ }^{1,4^{*}}$ (D)
}

\begin{abstract}
Although important advances in the management of breast cancer (BC) have been recently accomplished, it still constitutes the leading cause of cancer death in women worldwide. BC is a heterogeneous and complex disease, making clinical prediction of outcome a very challenging task. In recent years, gene expression profiling emerged as a tool to assist in clinical decision, enabling the identification of genetic signatures that better predict prognosis and response to therapy. Nevertheless, translation to routine practice has been limited by economical and technical reasons and, thus, novel biomarkers, especially those requiring non-invasive or minimally invasive collection procedures, while retaining high sensitivity and specificity might represent a significant development in this field. An increasing amount of evidence demonstrates that non-coding RNAs (ncRNAs), particularly microRNAs (miRNAs) and long noncoding RNAs (IncRNAs), are aberrantly expressed in several cancers, including BC. miRNAs are of particular interest as new, easily accessible, cost-effective and non-invasive tools for precise management of BC patients because they circulate in bodily fluids (e.g., serum and plasma) in a very stable manner, enabling BC assessment and monitoring through liquid biopsies. This review focus on how ncRNAs have the potential to answer present clinical needs in the personalized management of patients with $B C$ and comprehensively describes the state of the art on the role of ncRNAs in the diagnosis, prognosis and prediction of response to therapy in BC.
\end{abstract}

Keywords: Biomarkers, microRNA, Long nonconding RNA, Diagnostic, Prognostic

\section{Background}

Breast cancer $(\mathrm{BC})$ is one of the most common cancers with more than 1,300,000 cases diagnosed and 450,000 deaths occurring each year, worldwide [1]. Due to earlier diagnosis and implementation of adjuvant chemo- and hormone-therapies (HT), BC mortality has been declining, although it remains the most common cause of cancer-related death among women [2]. At present, most patients are diagnosed at localized disease stage, but $20-85 \%$ of all patients will eventually develop recurrent and/or metastatic disease [3].

$\mathrm{BC}$ is intrinsically heterogeneous, representing a spectrum of diseases with distinct morphology, molecular

\footnotetext{
*Correspondence: carmenjeronimo@ipoporto.min-saude.pt; cljeronimo@icbas.up.pt

${ }^{1}$ Cancer Biology and Epigenetics Group, IPO Porto Research Center (CI-IPOP), Portuguese Oncology Institute of Porto (IPOPorto), Research Center-LAB 3, F Bdg, 1 st floor, Rua Dr. António Bernardino de Almeida, 4200-072 Porto, Portugal

Full list of author information is available at the end of the article
}

traits, prognosis, and therapeutic options. On the basis of gene expression, $\mathrm{BC}$ cases are often classified into one of five intrinsic subtypes [4]. The large majority of estrogen receptor (ER) and/or progesterone receptor (PR)-positive $\left(^{+}\right)$tumors are of the luminal subtypes that typically express luminal cytokeratins (CK) 8 and 18 [5]. These tumors are further subdivided into Luminal $A$ and Luminal B, according to the expression levels of Ki67, a nuclear protein that is associated with cellular proliferation. The ER and PR-negative $\left(^{-}\right)$tumors are divided into three subtypes: the basal-like subtype, characterized by the expression of CK 5/6 and CK17; the human epidermal growth factor receptor 2 (HER2)-enriched subtype, which are positive for HER2; and the "normal-like" subtype, characterized by a similar gene expression pattern as the normal breast. This last subtype remains enigmatic as to whether it represents a separate subtype or a technical artifact introduced by the contamination of cancerous cells with their surrounding normal tissue [5]. 
$\mathrm{BC}$ clinical decisions are based on routine assays for ER, PR and HER2, as well as Ki67 [6]. The molecular phenotype of the tumor is indicative of the most suitable treatment, i.e., either endocrine therapy (ET) in hormone receptor positive or HER-targeted therapy in $\mathrm{HER}^{+}$tumors [7]. Globally, $\mathrm{ER}^{-}$tumors have a poorer prognosis in the first few years after diagnosis, but after 5-10 years, $\mathrm{ER}^{+}$tumors demonstrate the poorest outcome [8]. However, not all $\mathrm{ER}^{+} \mathrm{BCs}$ behave similarly, and the studies conducted in recent years show that luminal A and B BCs should be perceived as distinct entities [9]. Luminal A subtype has been shown to exhibit good clinical outcomes with ET whereas the pattern of mortality rates associated with the luminal B tumors is similar to those of the non-luminal subtypes [10]. However, Luminal $\mathrm{A}$, the most frequently occurring $\mathrm{BC}$ subtype, is also the most heterogeneous subtype, both molecularly and clinically [11]. Indeed, ER expression itself fails to predict which $\mathrm{ER}^{+}$tumors will respond or be resistant to different modalities of ET, and resistance has been reported in $30 \%$ of $\mathrm{ER}^{+} \mathrm{BCs}$ [12].

Due to molecular heterogeneity, clinical decisions based solely upon histopathologic analysis or one or small numbers of genes or their coding proteins in the tumor tissue are limited. Moreover, the widespread use of gene-expression profiling using commercially available molecular signatures for the examination of multiple expressed genes is also of limited application, primarily due to the cost and to reproducibility issues [13, 14].

Recently, several studies have reported on the association between microRNAs (miRNAs) and BC, suggesting its usefulness as disease biomarkers. Interestingly, miRNA detection in bodily fluids appear to have superior accuracy than messenger RNA (mRNA) profiling because of their high tissue-specificity, stability, and aberrant expression in different tumor types [15]. miRNAs have the additional advantage of being long-lived in vivo [16] and very stable in vitro $[17,18]$, which might be critical in a clinical setting. Indeed, tumor cells were suggested to release miRNAs stabilized by their association with RNA-binding proteins and by their incorporation into microvesicles $[19,20]$. The emergence of non-coding RNA (ncRNAs) as biomarkers may add robustness to the current molecular classification of human $\mathrm{BC}$, with the potential for improving diagnosis and monitoring of $\mathrm{BC}$. Thus, in this review, we will focus on ncRNAs as potential diagnostic, predictive and prognostic biomarkers for $\mathrm{BC}$ management.

\section{Evidence acquisition}

For the selection of bibliography, PubMed publications on $\mathrm{BC}$ were searched using the keywords breast cancer, noncoding RNAs and microRNAs. References of all articles were also examined for additional potentially relevant studies. The criteria for article selection were: written in English, central theme based on ncRNAs and BC. Original reports were selected based on the detail of analysis, mechanistic support of data, novelty, and potential clinical usefulness of the findings.

\section{Non-coding RNAS}

It is currently acknowledged that at least $98 \%$ of the mammalian genomes and other complex organisms are transcribed into ncRNAs [21]. In fact, ncRNAs that were previously thought to be "transcription noise", are believed to be a hidden layer of internal signals that control various levels of gene expression, playing a significant role in cell homeostasis and its deregulation is involved in the development of several human diseases. The family of ncRNAs, in addition to the well knows transfer RNAs (tRNAs), ribosomal RNAs (rRNAs), and small nucleolar RNAs (snoRNAs), includes the recently discovered long noncoding RNAs (lncRNAs) and miRNAs.

\section{Transfer RNA (tRNA)}

Transfer RNAs are small ncRNA transcripts, typically with 76-90 nucleotides (nt) in length, that serve as physical link between mRNA and the aminoacid sequence of proteins [22]. In 2009, Pavon-Eternod [23] analyzed genome-wide tRNA expression and found that tRNAs were increased in $\mathrm{BC}$ compared to normal breast tissues. Their results also suggested a functional consequence of tRNA over-expression in tumor cells, which seems to be selective and may increase the translational efficiency of genes relevant to cancer development and progression.

Recent studies indicated that precise cleavage of tRNAs generate active products [24]. Indeed, high levels of tRNA-derived miRNas or of tRNA-derived molecules termed $5^{\prime}$ tRNA halves are likely to be a manifestation of tRNA over-expression. Park [25] reported that miR1280-a tRNA-derived fragment was significantly up-regulated in blood of $\mathrm{BC}$ patients, particularly in metastatic $\mathrm{BC}$ patients, compared to healthy subjects and decreased significantly after systemic treatment in patients who responded to treatment, while increasing in the blood of patients with non-responding tumors. Moreover, $\mathrm{BC}$ is associated with expression deregulation-either increase or decrease-in the circulating levels of $5^{\prime}$ tRNA halves derived from specific tRNA isoacceptors [26], and changes in circulating $5^{\prime}$ tRNA halves were associated with specific tumor features, such as ER/ PR/HER2-status, raising the possibility of a causal connection with some aspects of breast carcinogenesis.

\section{Long noncoding RNAs (IncRNAs)}

LncRNAs are ncRNA molecules usually longer than 200 nts that do not fit into known classes of small or 
structural RNAs, and that may function as either primary or spliced transcripts [27]. LncRNAs may be transcribed from various genomic locations, as well as in their own stand-alone position in the genome-long intergenic non-coding RNAs (lincRNAs) [28]. LncRNAs have gained widespread attention in recent years as a potentially new and crucial layer of biological regulation, controlling cell cycle, apoptosis and differentiation by acting as protein-DNA or protein-protein scaffolds, miRNA sponges, protein decoys, and regulators of translation [29].

\section{LncRNAs in breast cancer}

LncRNAs were already found to be differentially expressed in $\mathrm{BC}$ tissues compared to normal breast tissues and recent studies have demonstrated their key regulatory role in gene expression and $\mathrm{BC}$ biology through diverse mechanisms [30].

\section{Diagnostic biomarkers}

Expression levels of lncRNAs have been investigated in $\mathrm{BC}$ tissues compared to normal tissues indicating that some may be potential biomarkers for $\mathrm{BC}$ diagnosis. Ding et al. found that lincRNA-BC2 and lincRNA-BC5 were consistently up-regulated (more than twofold) in $\mathrm{BC}$ samples, whereas lincRNA-BC4 and lincRNA-BC8 were down-regulated [31]. Moreover, lincRNA-BC4 expression was significantly lower in grade III $\mathrm{BC}$, and lincRNA-BC5 expression was significantly higher in grade III, whereas lincRNA-BC2' expression significantly associated with lymph node metastasis (LNM). Remarkably, lncRNAs' expression was also found to be highly associated with BC subtype classification [32]. Later studies have also demonstrated that lncRNAs are amenable for detection in bodily fluids. For example, the serum expression levels of circulating lncRNA RP11-445H22.4 were found significantly increased in BC patients, identifying BC cases with $92 \%$ sensitivity and $74 \%$ specificity [33].

\section{Prognostic biomarkers}

In addition to lncRNAs potential use as diagnostic biomarkers, they have been suggested as valuable prognostic biomarkers. Zhao and co-workers identified a set of lncRNAs that distinguished low-risk from highrisk BC patients [34]. Patients with significantly higher LINC00324 expression and lower PTPRG antisense RNA 1 (PTPRG-AS1) and small nucleolar RNA host gene 17 (SNHG17) expression showed longer overall survival (OS). In another study, high SPRY4 intronic transcript 1 (SPRY4-IT1) expression levels were also associated with poorer prognosis, specifically shorter disease-free survival (DFS) [35].
HOX transcript antisense RNA (HOTAIR) overexpression in $\mathrm{BC}$ tissues has been associated with higher invasion and metastatic capacities, and suggested as an OS and progression free-survival (PFS) biomarker [36]. Specifically, in $\mathrm{ER}^{+} \mathrm{BC}$ patients, HOTAIR expression was shown to independently predict the risk of metastasis [37]. Similarly, metastasis-associated lung adenocarcinoma transcript 1's (MALAT1) upregulation was found in primary $\mathrm{BC}$ and its levels were further increased in the respective metastases [38]. Conversely, BC040587 [39], neuroblastoma associated transcript 1 (NBAT1) [40] and eosinophil granule ontogeny transcript (EGOT) [41] were found downregulated in BC samples and associated with poor prognosis. Furthermore, LINC00472 high expression levels in $\mathrm{BC}$ tissues associated with less aggressive behavior and more favorable outcome [42].

\section{Predictive biomarkers}

LncRNAs have been suggested as valuable predictive biomarkers. Indeed, BC anti-estrogen resistance 4 (BCAR4) overexpression has been shown to predict tamoxifen resistance [43]. On the other hand, lincRNAs LINC00160 and LINC01016 were both found highly overexpressed in $\mathrm{ER}^{+}$tumors compared to $\mathrm{ER}^{-}$tumors and normal tissues, being significantly associated with longer OS of luminal A BC [44]. Interestingly, these lincRNAs may identify patients that respond to ET, functioning as robust predictive biomarkers for ER activity.

Besides ET resistance, progression or recurrence due to resistance to trastuzumab or other commonly used therapeutic approaches, such as chemotherapy and radiotherapy, also constitute a significant clinical challenge. LncRNA activated by TGF- $\beta$ (ATB) has been associated with trastuzumab resistance in BC patients [45]. Conversely, lncRNA colon cancer associated transcript 2 (CCAT2) overexpression identified a subset of BC patients that might not benefit from cyclophosphamide, methotrexate and fluorouracil (CMF) based adjuvant chemotherapy [46]. Finally, Chen et al. [47] demonstrated that overexpression of lincRNA Regulator of Reprogramming (ROR) is associated chemotherapy tolerance.

\section{microRNAs (miRNAs)}

miRNAs are endogenous, small non-coding singlestranded RNAs with an approximate length of $22 \mathrm{nt}$, encoded by various genomic regions in either sense or antisense orientation [48]. miRNAs are critical for a wide range of biological processes exerting a finely tuned regulation of gene expression at posttranscriptional level [49].

\section{miRNAs in breast cancer}

miRNA dysregulation in cancer was first reported in 2002 [50]. Since then, the emergence of miRNAs has 
been one of the defining developments in cancer biology with several studies demonstrating a differential miRNA expression profile and global miRNA downregulation in human malignancies compared with paired normal tissues. Indeed, aberrant miRNA expression in human tumors is not just a casual association, as it exerts a causal role at different steps of the tumorigenic process. Some of the miRNAs that will be mentioned here have already been associated with several hallmarks of cancer [3, 51, 52] (Fig. 1).

miRNAs might be classified into oncogenic miRNAs (oncomiRs) or tumor suppressor miRNAs, depending on their targets. OncomiRs act by repressing the expression of tumor suppressor genes and are frequently upregulated in cancer. Tumor suppressor miRNAs act by targeting oncogenes and are frequently downregulated in cancer. However, this miRNA categorization may be inaccurate, as many studies have shown that miRNAs may present a dual function, with oncogenic or tumor suppressive properties based on tumor type and cellular context [53]. Furthermore, some miRNAs are consistently up- or down-regulated in tumor specimens, whereas other, such as miR-221 and miR-10b, exhibit a more irregular pattern of expression [54]. MiR-10b was found downregulated in all BCs from metastasis-free patients, but elevated miR-10b levels were found in primary tumors from patients harboring metastasis, suggesting that miR-10b might be differentially deregulated along tumor progression [55]. Volinia et al. [56] studied this change in miRNA expression along cancer progression and found that let-7d, miR-210 and miR-221 were downregulated in the ductal carcinoma in situ compared to normal breast tissue, but it was found to be upregulated in the transition to invasive carcinoma, featuring an expression reversal along the cancer progression path.

\section{Diagnostic biomarkers}

Each tumor type has a distinct miRNA signature that distinguishes it from normal tissues and other cancer types [15]. In 2005, Iorio et al. [57] identified a 13-miRNA signature that could discriminate $\mathrm{BC}$ from normal breast tissues with perfect accuracy. Among the differentially expressed miRNAs, the most consistently dysregulated were miR-125b and miR-145 (downregulated), and miR21 (up-regulated). Since then, many studies have looked at specific miRNAs dysregulated in $\mathrm{BC}$ with a diagnostic purpose.

In addition to studies of miRNA expression patterns in tissues, expression profiling studies of miRNAs in bodily fluids have been performed, to investigate whether bodily fluids could be used to differentiate $\mathrm{BC}$ patients from healthy individuals. In this context, Heneghan et al. [58] found significantly higher levels of miR-195 and let-7a in the blood of BC patients compared to healthy controls, detecting $\mathrm{BC}$ with high sensitivity and specificity. Several studies have also highlighted differences in the profiles of serum and plasma miRNAs in cancer compared to healthy individuals. MiR-222, for example, was significantly increased in the serum of BC patients [59], while higher miR-205 levels have been found in the sera of healthy individuals compared to BC patients [60]. Furthermore, Zhao et al. found that miR-195 was downregulated in the plasma of $\mathrm{BC}$ patients compared to healthy subjects [61].

miRNA profiles show better diagnostic performance as well as increased sensitivity than individual miRNAs, for $\mathrm{BC}$ detection. Hu et al. identified a 4-miRNA signature with increased concentrations in the serum of $\mathrm{BC}$ patients that could distinguish $\mathrm{BC}$ patients from healthy individuals with 92.1 and $93.4 \%$ sensitivity and specificity, respectively [62]. More recently, Zhang and coworkers have found a 3-miRNA signature in serum as a diagnostic biomarker for non-invasive early detection of BC [63], whereas Ng et al. reported that the combination of miR-145 and miR-451 levels in plasma may discriminate normal individuals from $\mathrm{BC}$ patients, both at early and advanced stages of disease [64]. Finally, Cuk et al. have also found a panel of deregulated plasma miRNAs that were elevated in women with benign and stage I or II $\mathrm{BC}$, that might be attractive candidates for early $\mathrm{BC}$ detection [65].

Table 1 summarizes these and others non-circulating and circulating miRNAs already described and validated in large cohorts for $\mathrm{BC}$ diagnosis.

Despite the identification of non-circulating and circulating miRNAs aberrantly expressed in $\mathrm{BC}$, discrepancies remain among the different miRNA signatures reported, probably due to differences in clinicopathological variables and the intrinsic heterogeneity of $\mathrm{BC}$. Therefore, an attempt has been made to develop miRNA signatures that might reflect distinct histopathological features of BC.

Indeed, altered miRNAs levels that predict ER, PR and HER2 receptor status have already been identified (Table 2). Lowery et al. identified a 15-miRNA predictive signature corresponding to the expression of ER, PR, and HER2 receptor status [74]. Recently, Cizeron-Clairac and co-workers found that 20 miRNAs were significantly deregulated in $\mathrm{ER}^{+}$compared to $\mathrm{ER}^{-} \mathrm{BCs}$ [75]. Up-regulation of miR-1244 and downregulation of miR-30e were specific of $\mathrm{ER}^{-}$tumors, whereas downregulation of miR18a, miR-18b and miR-654-3p and up-regulation of miR342-5p and miR-190b were specific of $\mathrm{ER}^{+}$tumors.

Circulating miRNAs were also found to correlate with ER, PR and HER2 status in several studies. For example, higher levels of circulating miR-182 [77], miR-21 and 


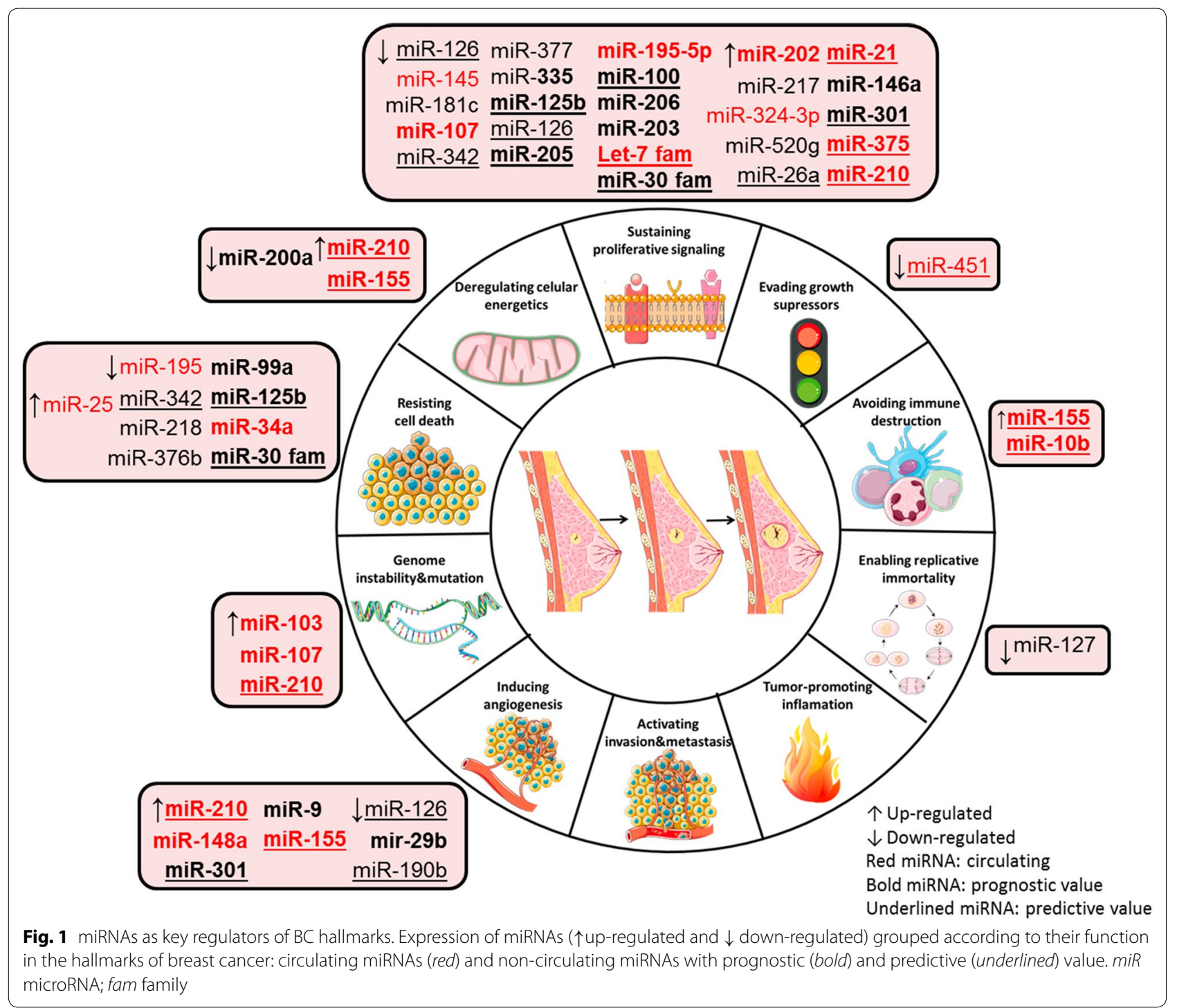

miR-10b [58] have been correlated with ER/PR ${ }^{-}$tumors. Furthermore, miR-155 expression levels were higher in sera of women with hormone-sensitive BCs [79]. Moreover, higher levels of circulating miR-375 were associated with ER/PR ${ }^{-}$and HER2 ${ }^{+}$tumors, whereas higher levels of circulating miR-122 associated with HER2 ${ }^{-}$tumors [78].

Several specific miRNA expression profiles have also been associated with $\mathrm{BC}$ molecular subtypes. Iorio et al. identified a distinct miRNA signature in luminal BC, with overexpression of miR-191 and miR-26 and downregulation of miR-206 [57]. Likewise, miRNAs might differentiate between basal and luminal tumor subtypes in an independent data set [81]. In an attempt to capture the heterogeneity of Luminal A and Luminal B BCs, Endo et al. compared the expression profiles of miRNAs in $\mathrm{ER}^{+}$ tissues between $\mathrm{ER}^{\text {high }} / \mathrm{Ki} 67^{\text {low }}$ tumors and $\mathrm{ER}^{\text {low }} / \mathrm{Ki} 67^{\text {high }}$ tumors [82]. They found that six miRNAs (let-7a, miR15a, miR-26a, miR-34a, miR-193b and miR-342-3p) were upregulated and a single miRNA was downregulated (miR-1290) in $\mathrm{ER}^{\text {high }} / \mathrm{Ki67} 7^{\text {low }}$ tumors [82].

\section{Prognostic biomarkers}

miRNAs have been correlated with clinical and pathological features that associate with prognosis in different tumor types and subgroups of $\mathrm{BC}$ patients [83, 84]. The search for prognostic biomarkers is a continuous and fundamental work in progress, since patients at higher risk may require differential therapeutic interventions.

One of the main reasons for the $\mathrm{BC}$ associated mortality is metastization [85], a complex process that allows the primary tumor cells to spread to the neighboring as 
Table 1 Non-circulating and circulating miRNAs for BC diagnosis

\begin{tabular}{|c|c|c|c|c|c|c|c|c|}
\hline & miRNAs & Sample & $\begin{array}{l}\text { Validation } \\
\text { techniques }\end{array}$ & Samples size & Sensitivity & Specificity & AUC & Refs \\
\hline \multirow[t]{3}{*}{$\begin{array}{l}\text { Non-circulating } \\
\text { miRNAs }\end{array}$} & $\uparrow m i R-23 a$ & BC tissues & qRT-PCR & $\begin{array}{l}76 \mathrm{BC} \text { vs. } 36 \text { benign } \\
\text { vs. } 36 \mathrm{~N}\end{array}$ & 0.829 & 0.100 & 0.915 & {$[66]$} \\
\hline & $\begin{array}{c}\uparrow m i R-155,-21,-184 \\
-518 b,-572,-601 \\
-622 \downarrow m i R-125 b\end{array}$ & & TaqMan qRT-PCR & $24 \mathrm{BC}$ vs. $6 \mathrm{~N}$ & - & - & - & {$[67]$} \\
\hline & $\begin{array}{l}\uparrow m i R-660-5 p \\
\downarrow \text { miR-99b-5p, -574- } \\
3 p,-769-5 p\end{array}$ & & SYBR Green qRT-PCR & $\begin{array}{l}56 \mathrm{BC} \text { vs. } 9 \mathrm{~N} \\
60 \mathrm{BC} \text { vs. } 11 \mathrm{~N}\end{array}$ & - & - & - & [68] \\
\hline \multirow[t]{12}{*}{ Circulating miRNAs } & $\uparrow m i R-222$ & Serum & qRT-PCR & $50 \mathrm{BC}$ vs. $50 \mathrm{~N}$ & 0.74 & 0.60 & 0.671 & [59] \\
\hline & $\begin{array}{l}\uparrow m i R-16,-25,-222, \\
-324-3 p\end{array}$ & & TaqMan qRT-PCR & $76 \mathrm{BC}$ vs. $76 \mathrm{~N}$ & 0.921 & 0.934 & 0.928 & {$[62]$} \\
\hline & $\uparrow m i R-145,-155,-382$ & & qRT-PCR & $61 \mathrm{BC}$ vs. $10 \mathrm{~N}$ & 0.976 & 0.100 & 0.988 & [69] \\
\hline & $\downarrow \mathrm{miR}-205$ & & qRT-PCR & $58 \mathrm{BC}$ vs. $93 \mathrm{~N}$ & 0.862 & 0.828 & 0.84 & {$[60]$} \\
\hline & $\uparrow m i R-199 a,-29 c,-424$ & & SdM-RT-PCR & $76 \mathrm{BC}$ vs. $52 \mathrm{~N}$ & 0.776 & 0.846 & 0.901 & [63] \\
\hline & $\uparrow m i R-92 a, m i R-133 a$ & & qRT-PCR & $132 \mathrm{BC}$ vs. $101 \mathrm{~N}$ & - & - & 0.91 & [70] \\
\hline & $\downarrow \mathrm{miR}-200 \mathrm{c}$ & Whole blood & qRT-PCR & $57 \mathrm{BC}$ vs. $20 \mathrm{~N}$ & 0.90 & 0.702 & 0.79 & [71] \\
\hline & $\downarrow m i R-145 \uparrow m i R-451$ & Plasma & TaqMan qRT-PCR & $70 \mathrm{BC}$ vs. $50 \mathrm{~N}$ & 0.900 & 0.920 & 0.931 & [64] \\
\hline & $\begin{array}{c}\uparrow m i R-127-3 p,-148 b \\
-376 a,-376 c,-409- \\
3 p,-652,-801\end{array}$ & & TaqMan qRT-PCR & $120 \mathrm{BC}$ vs. $60 \mathrm{~N}$ & 0.800 & 0.720 & 0.81 & {$[65]$} \\
\hline & $\downarrow$ miR-195 & & SYBR Green qRT-PCR & $210 \mathrm{BC}$ vs. $102 \mathrm{~N}$ & 0.69 & 0.892 & 0.859 & {$[61]$} \\
\hline & $\begin{array}{c}\uparrow \text { miR-16, -148a, -19b, } \\
-22 a \downarrow \text { Let-7d, let-7i, } \\
\text { miR-103,-107 }\end{array}$ & & qRT-PCR & $108 B C$ vs. $88 \mathrm{~N}$ & 0.91 & 0.49 & 0.81 & [72] \\
\hline & $\begin{array}{l}\uparrow m i R-505-5 p \\
\uparrow m i R-96-5 p\end{array}$ & & qRT-PCR & $114 \mathrm{BC}$ vs. $116 \mathrm{~N}$ & - & - & $\begin{array}{l}0.72 \\
0.72\end{array}$ & [73] \\
\hline
\end{tabular}

${ }^{\uparrow}$ Up-regulated ${ }^{\downarrow}$ Down-regulated

$N$ normal, SdM serum-direct multiplex

Table 2 miRNAs which increased expression predicts for ER, PR and HER2 receptor status in BC

\begin{tabular}{|c|c|c|}
\hline & & Refs. \\
\hline \multicolumn{3}{|c|}{ ER status } \\
\hline $\mathrm{ER}^{+}$ & miR-342, $-217,-190 b,-218,-342-5 p$ & [74-76] \\
\hline $\mathrm{ER}^{-}$ & $\begin{array}{l}\text { miR-299-3p, }-190,-135 b,-182,-21,-30 e \\
-1244,-10 b,-375\end{array}$ & {$[58,74,75,77,78]$} \\
\hline \multicolumn{3}{|c|}{ PRstatus } \\
\hline $\mathrm{PR}^{+}$ & miR-520f-520c, $-377,-155$ & {$[74,79]$} \\
\hline $\mathrm{PR}^{-}$ & $\begin{array}{l}\text { miR-520 g, }-527-518 \mathrm{a},-182,-10 b,-375 \\
-21\end{array}$ & {$[74,77,78]$} \\
\hline \multicolumn{3}{|c|}{ HER2 status } \\
\hline HER2 ${ }^{+}$ & miR-520d, $-376 b,-146 a-5 p,-375$ & {$[74,80]$} \\
\hline HER2- & miR-181c, -122 & {$[74,78]$} \\
\hline
\end{tabular}

Circulating miRNAS are represented in italic well as to distant parts of the organism. miRNAs appear to be involved in the phenotypic changes associated with metastasis formation, such as epithelial-mesenchymal transition, as well as with the presence of circulating tumor cells, which correlate with metastatic spread [86]. miRNAs may act either as promotors of $\mathrm{BC}$ metastasis or as metastasis suppressors. Metastasis promoters include miR-9 [87], miR-10b [55, 88], miR-21 [89], miR-29a [90], miR-155 [91], miR-520c [92], miR-373 [88, 92], miR-214 [93], miR-301 [94] and miR-548j [95], whereas metastasis suppressors include miR-17/20 [96], miR-126 [97], miR-193b [98], miR-206 [99], miR-335 [100], miR-448 [101], miR-601 [102], miR-138 [103], miR-515-5p [104], miR-203 [105], miR-200 family and miR-205 [106]. These specific miRNAs might serve as valuable biomarkers 
for predicting metastasis and tumor recurrence, which determine the unfavorable prognosis of $\mathrm{BC}$ patients. All these miRNAs were validated in tumor tissues and/or bodily fluids from BC patients and are depicted in Fig. 2.

miRNAs have also been associated with other clinical and pathological features that influence BC patients' prognosis. miR-21, aside from being a driver of metastasis, has been known to create a pro-tumorigenic environment by targeting numerous tumor suppressor genes, and its overexpression was correlated with advanced tumor stage and poor OS and DFS in BC patients [107, 108]. Several studies have independently associated miR210 with $B C$ development and its expression levels were correlated with tumor aggressiveness and poor prognosis $[109,110]$. Moreover, some miRNAs have been associated with a good prognosis, such as the miR-30 family, that has been identified as an individual favorable prognostic marker in several studies [111-113]. Other miRNAs, particularly downregulation of the miR-200 family, have also been associated with $\mathrm{BC}$ stem cells [114], one of the main obstacles for effective treatment of BC [115].

Some studies have focused on particular subtypes of BC. Bailey et al. evaluated miRNAs expression in $\mathrm{ER}^{+}$ $\mathrm{BC}$ tissues and found that a cluster comprising let-7c and
miR-125b was uniformly low in luminal $B$ and lost in a subset of luminal A patients with worse OS, indicating its potential as biomarker of good outcome in $\mathrm{ER}^{+}$luminal A BC patients [116]. Gasparini and co-workers identified a 4-microRNA signature in triple negative $B C$ that allowed for the stratification of those patients into highand low-risk groups [117]. Up-regulation of miR-493 and miR-155 correlated with better patient outcome, whereas miR-30e and miR-27a downregulation correlated with worse outcome [117].

Interestingly, some miRNAs may differentially influence outcome depending on the characteristics of the tumors. Tuomarila et al. reported that high miR-200c expression independently predicted poor OS in patients with $\mathrm{PR}^{-}$tumors, whereas low expression independently predicted poor OS in patients with $\mathrm{PR}^{+}$tumors [118].

These and other miRNA signatures or single miRNAs that have been associated with prognosis are summarized in Table 3.

\section{Predictive biomarkers}

The role of miRNAs as potential predictive biomarkers is also a field of growing interest. When investigating the regulation of miRNAs expression by antiestrogen

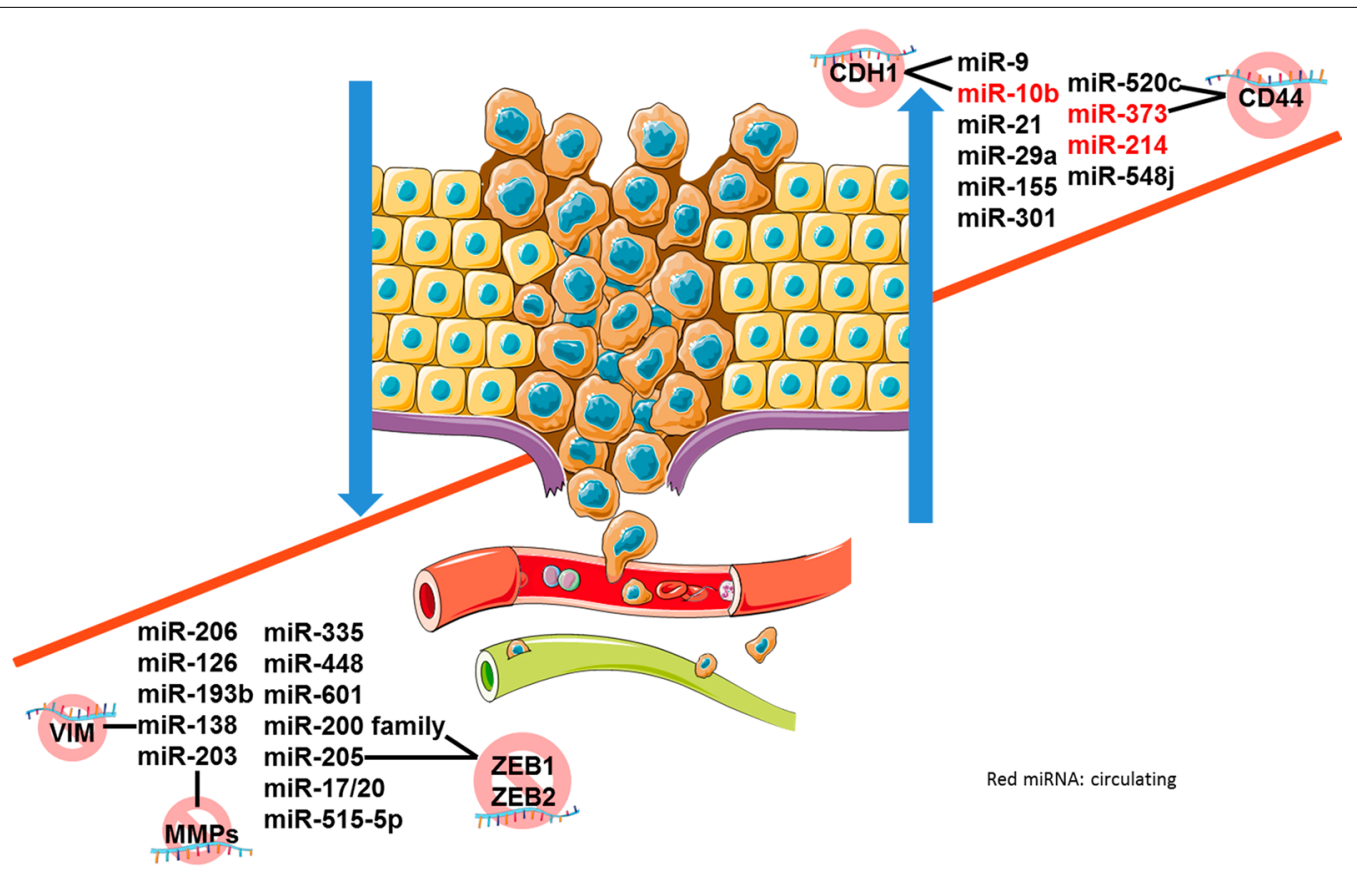

Fig. 2 miRNAs and breast cancer metastasis. miRNAs are crucial in metastatic spreading, acting either as oncogenes, typically up-regulated, or as tumor suppressor genes, typically down-regulated. Circulating (red), non-circulating miRNAs and examples of targets. miR microRNA, CD cluster of differentiation, ZEB Zinc Finger E-Box binding homeobox 1, MMPs matrix metalloproteinases, VIM vimentin, CDH1 cadherin 1 
Table 3 miRNA panels or single miRNAs proposed with a prognostic aim

\begin{tabular}{|c|c|c|c|c|}
\hline & miRNA & Biological sample & Consequences & Refs. \\
\hline \multirow[t]{20}{*}{ miRNAs associated with positive outcome } & miR-100 & Tumor tissues & $\uparrow O S$ & [119] \\
\hline & $\operatorname{miR}-29 c$ & & & [120] \\
\hline & miR-181d, $-195-5 p$ & & & [80] \\
\hline & miR-128 & & & [121] \\
\hline & Let-7b, miR-205 & & $\uparrow R F S$, OS & [122] \\
\hline & miR-342-5p & & & [123] \\
\hline & miR-497 & & $\downarrow T N M$, LNM & [124] \\
\hline & miR-133a & & $\uparrow R F S$ & [125] \\
\hline & miR-30 family & & $\begin{array}{l}\uparrow \text { OS, RFS, DFS } \\
\downarrow \text { Metastasis }\end{array}$ & [111-113] \\
\hline & miR-206 & & $\uparrow O S \downarrow T N M$, LNM & [126] \\
\hline & miR-601 & & $\downarrow$ Metastasis $\uparrow$ MFS & [102] \\
\hline & miR-124 & & $\uparrow O S \downarrow T N M, L N M$ & [127] \\
\hline & miR-138 & & $\downarrow T N M$, LNM & [103] \\
\hline & miR-190b & & $\uparrow M F S, O S$ & [75] \\
\hline & miR-200b & & $\downarrow L N M$ & [128] \\
\hline & miR-29b & & $\uparrow D F S, O S$ & [129] \\
\hline & miR-27a & & & [130] \\
\hline & $\begin{array}{l}\operatorname{miR}-374 b-5 p,-218-5 p \\
-126-3 p\end{array}$ & TNBC tissues & $\uparrow D F S, O S$ & [131] \\
\hline & miR-155 -493 & & $\uparrow O S$ & [117] \\
\hline & let-7c, miR-99a, -125b & Luminal A BC tissues & $\uparrow O S$ & [116] \\
\hline \multirow[t]{22}{*}{ miRNAs associated with negative outcome } & miR-21 & Tumor tissues & $\begin{array}{l}\uparrow \text { Grade, TNM, LNM, metastasis } \\
\downarrow D F S, \text { RFS, OS }\end{array}$ & {$[107,108]$} \\
\hline & $\operatorname{miR}-210$ & & $\downarrow$ OS, RFS, DFS, MFS $\uparrow$ Grade & [109] \\
\hline & miR-23a & & $\downarrow R F S$ & [66] \\
\hline & miR-423 & & $\uparrow$ Metastasis & [132] \\
\hline & miR-9 & & $\uparrow$ Grade, metastasis, LR & [87] \\
\hline & miR-187 & & $\downarrow D S S$, RFS & [133] \\
\hline & miR-155 & & $\uparrow T N M$, grade, LNM $\downarrow$ OS & [134] \\
\hline & miR-221/222 & & $\downarrow M F S$ & [135] \\
\hline & miR-421, $-486,-503,-720,-1303$ & & $\downarrow M F S$ & [136] \\
\hline & miR-375 & & $\uparrow L R$ & [137] \\
\hline & miR-548 family & & $\uparrow L N M \downarrow M F S$ & [95] \\
\hline & miR-146a-5p & & $\downarrow$ OS & [80] \\
\hline & miR-27b-3p & TNBC tissues & $\uparrow$ Metastasis $\downarrow$ DSS & [138] \\
\hline & miR-93 & & $\uparrow L N M$, TNM, grade, Ki-67 & [139] \\
\hline & miR-21, $-210,-221$ & & $\downarrow D F S, O S$ & [140] \\
\hline & miR-34b & & & [141] \\
\hline & miR-18b, -103, -107, -652 & TNBC patients serum & $\downarrow O S, R F S$. & [142] \\
\hline & miR-200b & BC patients plasma & $\downarrow P F S$, OS & [86] \\
\hline & miR-202 & BC patients serum & $\downarrow$ OS & [143] \\
\hline & miR-10b-5p & & 个TNM, grade, LNM & [144] \\
\hline & miR-122 & & $\downarrow M F S, R F S$ & [78] \\
\hline & miR-10b, -34a, -155 & & $\uparrow$ Metastasis & [145] \\
\hline
\end{tabular}

${ }^{\uparrow}$ Incresead; ${ }^{\downarrow}$ Decreased

RFS relapse-free survival, TNM TNM classification of malignant tumours, MFS metastasis-free survival, $L R$ local recurrence, DSS disease-specific survival 
therapies in human $\mathrm{BC}$ specimens using the initial biopsy and comparing it with the surgery specimen after neoadjuvant ET, Maillot and co-workers [146] noticed that some miRNAs that were previously shown overexpressed in tamoxifen-resistant cell lines were up-regulated following ET. These results highlight the utility of considering miRNA expression in understanding ET resistance in BC. Other studies have searched for miRNAs able to predict therapeutic response of BC patients to ET. For instance, Rodriguez-Gonzalez and colleagues [147] have found that miR-30c independently predicted clinical benefit of tamoxifen therapy in patients with advanced BC. On the other hand, Rothe et al. [110] found that miR-210 high level expressions were associated with a higher risk of recurrence in tamoxifen treated patients.

In addition to ET, miRNAs have been involved in responsiveness to other therapies. For instance, high circulating levels of miR-210 have been associated with resistance to anti-HER2 therapy using trastuzumab [148] and miR-100 expression has been positively correlated with sensitivity to chemotherapy using paclitaxel [119]. The potential role of miRNAs in the prediction of the response to these and other therapies, such as radiotherapy, are summarized in Table 4.

Several clinical trials, summarized in Table 5, are currently ongoing to address the role of miRNAs in diagnosis, prognosis and prediction of response to therapy, aiming at the translation of current knowledge on miRNAs in BC into clinical practice.

\section{Conclusion}

$\mathrm{BC}$ is a very heterogeneous disease, and several biological features are routinely used for diagnostic, prognostic and predictive purposes, including histological grade, lymph node status, hormone receptor status, and HER2 status. These factors have been associated with BC patient's survival and clinical outcome following treatment. Nevertheless, some patients with similar combination of those features follow different clinical paths, demonstrating that the capacity of determining prognosis and predicting therapeutic outcome in $\mathrm{BC}$ patients remains limited. Several mRNA-based tests are currently available with the aim of improving $\mathrm{BC}$ prognostication, but its use in clinical practice is still limited. New biomarkers are therefore needed to assist in improving $\mathrm{BC}$ patient prognostication and monitoring, allowing for a more precise definition of the therapeutic and follow-up strategy in an individual basis.

Based on the studies cited in this review, it is remarkable that ncRNAs are adding an extra dimension to the understanding of $\mathrm{BC}$ biology. miRNAs, in particular, are emerging as promising biomarkers for $\mathrm{BC}$ diagnosis (e.g. miR-155 and miR-195), prognosis (e.g. miR-29b and miR30 family) and prediction of response to therapy (e.g. miR$30 \mathrm{c}$ and miR-221). It should be emphasized that miRNAs are easily accessible, affordable, non-invasive tools for personalized management of $\mathrm{BC}$ patients, since they circulate stably in bodily fluids. These features allow miRNAs to respond to current clinical needs and provide the opportunity to bypass the problems associated with tumor tissue biopsy. Although some lncRNAs have also shown potential to serve as $\mathrm{BC}$ biomarkers, the stability and origin of circulating lncRNAs remain largely unknown, and additional studies are required to support a definitive clinical application. Regarding tRNAs, many questions also remain unanswered, such as the origin and its physiological role.

When reviewing the data from several studies, widespread inconsistencies across them are found. The cause might be attributable to differences in sample type, with some studies using plasma or serum and other using whole blood, differences in technology platforms used for miRNA profiling, such as next-generation sequencing (NGS) or real time reverse transcription polymerase chain reaction, differences in the choice of pre- or-postoperative samples, as well as from the choice of different genes for data normalization. These discrepancies among reported signatures highlight the need to standardize experimental conditions for circulating miRNAs studies, as well as the need to validate these findings in additional independent cohorts as well as preclinical/clinical verification studies, before the clinical utility of circulating miRNAs may be established.

In conclusion, the emergence of ncRNA classes as possible $\mathrm{BC}$ biomarkers, mainly miRNAs, shows great potential to foster precision medicine in $\mathrm{BC}$, although its application in clinical routine is still a long term goal. 
Table 4 miRNAs involved in therapeutic response (sensitivity/resistance) in BC

\begin{tabular}{|c|c|c|c|c|c|c|}
\hline Therapies & Role in response & miRNA & Putative targets & Agent & Biological samples & Refs. \\
\hline \multicolumn{7}{|l|}{ Hormone therapy } \\
\hline \multirow[t]{9}{*}{ Antiestrogens } & Sensitivity & miR-342 & CCNB1 & Tamoxifen & $\begin{array}{l}\text { Cell lines and tumor } \\
\text { tissues }\end{array}$ & [149] \\
\hline & & miR-26a & $\mathrm{EZH} 2$ & & Tumor tissues & [150] \\
\hline & & miR-30c & EGFR & & & {$[147]$} \\
\hline & & miR-10, -126 & - & & & [151] \\
\hline & Resistance & miR-221/222 & CDKN1B & Tamoxifen, fulvestrant & $\begin{array}{l}\text { Tumor tissues and cell } \\
\text { lines }\end{array}$ & {$[152,153]$} \\
\hline & & miR-519a & CDKN1B PTEN, RB1 & Tamoxifen & $\begin{array}{l}\text { Tumor tissues and cell } \\
\text { lines }\end{array}$ & {$[154]$} \\
\hline & & miR-155 & socs6 & & & [131] \\
\hline & & miR-210 & - & & Tumor tissues & [110] \\
\hline & & miR-301 & $\begin{array}{l}\text { FOXF2, BBC3, PTEN, } \\
\text { COL2A1 }\end{array}$ & & $\begin{array}{l}\text { Tumor tissues, cell lines } \\
\text { and xenografts }\end{array}$ & [94] \\
\hline \multirow[t]{2}{*}{ Aromatase inhibitors } & Sensitivity & miR-125b let-7c & ERBB2 & Letrozole, anastrozole & $\begin{array}{l}\text { Tumor tissues and cell } \\
\text { lines }\end{array}$ & [116] \\
\hline & Resistance & miR-181a & BCL2L11 & Letrozole & $\begin{array}{l}\text { Cell lines, xenografts } \\
\text { and tumor tissues }\end{array}$ & {$[155]$} \\
\hline \multirow[t]{2}{*}{ Antibodies } & Sensitivity & miR-210 & - & Trastuzumab & Cell lines and plasma & {$[148]$} \\
\hline & Resistance & miR-21 & PTEN & Trastuzumab & $\begin{array}{l}\text { Cell lines, xenograft and } \\
\text { tumor tissues }\end{array}$ & [156] \\
\hline \multirow[t]{11}{*}{ Chemotherapy } & Sensitivity & $\operatorname{miR}-451$ & MRP-1 & Doxorubicin & $\begin{array}{l}\text { Cell lines and tumor } \\
\text { tissues }\end{array}$ & {$[157]$} \\
\hline & & miR-200c & MRP-1 & & & [158] \\
\hline & & $\operatorname{miR}-134$ & $\mathrm{ABCC} 1$ & & & [159] \\
\hline & & $\operatorname{miR}-128$ & $\mathrm{BMI} 1, \mathrm{ABCC} 5$ & Doxorubicin, Paclitaxel & $\begin{array}{l}\text { Cell lines, xenografts } \\
\text { and tumor tissues }\end{array}$ & {$[121]$} \\
\hline & & miR-100 & MTOR & Paclitaxel & $\begin{array}{l}\text { Cell lines, xenografts } \\
\text { and luminal tumor } \\
\text { tissues }\end{array}$ & [119] \\
\hline & & miR-16 & IKBKB & & $\begin{array}{l}\text { Cell lines and tumor } \\
\text { tissues }\end{array}$ & {$[160]$} \\
\hline & & miR-621 & FBX011 & Paclitaxel + Carboplatin & $\begin{array}{c}\text { Cell lines, xenografts } \\
\text { and tumor tissues }\end{array}$ & {$[161]$} \\
\hline & Resistance & miR-125b & $\mathrm{BAK} 1, \mathrm{E} 2 \mathrm{~F} 3$ & FEC & $\begin{array}{l}\text { Cell lines, tumor tissues } \\
\text { and serum }\end{array}$ & {$[162]$} \\
\hline & & miR-141 & - & Taxane, Anthracyclines & $\begin{array}{l}\text { Cell lines and tumor } \\
\text { tissues }\end{array}$ & [163] \\
\hline & & $\operatorname{miR}-221$ & CDKN1B & & Plasma & {$[164]$} \\
\hline & & miR-155 & $\mathrm{FOXO3a}$ & $\begin{array}{l}\text { Paclitaxel, VP-16, Doxo- } \\
\text { rubicin }\end{array}$ & $\begin{array}{l}\text { Cell lines and tumor } \\
\text { tissues }\end{array}$ & {$[165]$} \\
\hline Radiotherapy & Sensitivity & miR-155 & RAD51 & - & $\begin{array}{l}\text { Cell lines and TNBC } \\
\text { tissues }\end{array}$ & {$[166]$} \\
\hline
\end{tabular}

CCNB1 cyclin B1, EZH2 enhancer of zeste homolog 2, EGFR epidermal growth factor receptor, CDKN1B cyclin-dependent kinase inhibitor 1B, PTEN phosphatase and tensin homolog, RB1 retinoblastoma 1, SOCS6 suppressor of cytokine signaling 6, FOXF2 forkhead box F2, BBC3 BCL2 binding component 3, COL2A1 collagen type II alpha 1,ERBB2 Erb-B2 receptor tyrosine kinase 2, $B C L 2 L 11 \mathrm{BCl}$-2-like protein 11, MRP1 multidrug resistance-associated protein 1, $A B C C 1$ ATP binding cassette subfamily $C$ member 1, BMI1 BMI1 polycomb ring finger oncogene, $A B C C 5$ ATP binding cassette subfamily $C$ member 5 , MTOR mechanistic target of rapamycin, IKBKB IKB kinase $\beta, F B X 011$ F-box protein 11, BAK1 BCL2 antagonist/killer 1, E3F3 E2F transcription factor 3, FOXO3a Forkhead box O3a, RAD51 RAD51 recombinase, FEC 5-florouracil, epirubucin and cyclophosphamide 
Table 5 Ongoing clinical trials aiming at the introduction of miRNAs in clinical practice

\begin{tabular}{|c|c|c|c|c|}
\hline Clinical trial & Patient population & Intervention & Aims & Study start date \\
\hline NCT00581750 observational & $\begin{array}{l}\text { Patients with lobular carcinoma } \\
\text { in situ }\end{array}$ & Tumor profiling & Diagnosis & October 2001 \\
\hline NCT01231386 observational & $\begin{array}{l}\text { Patients undergoing neoadjuvant or } \\
\text { adjuvant chemotherapy and HT for } \\
\text { locally advanced and inflamma- } \\
\text { tory BC }\end{array}$ & $\begin{array}{l}\text { Tumor profiling, Circulating } \\
\text { miRNAs }\end{array}$ & Prognosis drug sensitivity & October 2014 \\
\hline NCT01722851 observational & $\begin{array}{l}\text { Newly diagnosed BC patients who } \\
\text { are scheduled to undergo } \\
\text { neoadjuvant chemotherapy/HT } \\
\text { and patients who present with } \\
\text { disease recurrence or disease pro- } \\
\text { gression, and who are commenced } \\
\text { on systemic therapies (HT and/or } \\
\text { chemotherapy) }\end{array}$ & Circulating miRNAs & Prognosis drug sensitivity & September 2013 \\
\hline NCT02656589 observational & $\begin{array}{l}\text { Patients with } \mathrm{HER} 2^{+} \text {advanced } \\
\text { stage } \mathrm{BC} \text { who were treated with } \\
\text { herceptin }\end{array}$ & & Drug sensitivity & June 2015 \\
\hline NCT01598285 observational & $\begin{array}{l}\text { Patients suffering from metastatic } \\
\text { BC, treated with bevacizumab }\end{array}$ & & & May 2012 \\
\hline NCT01612871 observational & $\begin{array}{l}\text { Patients with metastatic invasive } \mathrm{BC} \\
\text { or locally advanced } \mathrm{BC} \text { for which } \\
\text { treatment with tamoxifen or anti- } \\
\text { aromatase is indicated }\end{array}$ & & & June 2012 \\
\hline
\end{tabular}

\begin{abstract}
Abbreviations
BC: breast cancer; BCAR4: BC anti-estrogen resistance 4; CCAT2: IncRNA colon cancer associated transcript 2; CMF: cyclophosphamide, methotrexate and fluorouracil; DFS: disease-free survival; EGOT: eosinophil granule ontogeny transcript; ER: estrogen receptor; PR: progesterone receptor; HER2: human epidermal growth factor receptor 2; ET: endrocrine therapy; HOTAIR: HOX transcript antisense RNA; HT: hormone-therapies; LincRNAs: long intergenic non-coding RNAs; IncRNAs: long noncoding RNAs; LNM: lymph node metastasis; MALAT1: metastasis-associated lung adenocarcinoma transcript 1; miRNAs: microRNAs; mRNA: messenger RNA; NBAT1: neuroblastoma associated transcript 1; ncRNAs: noncoding RNAs; OncomiRs: oncogenic miRNAs; OS: overall survival; PFS: progression free-survival; PTPRG-AS1: PTPRG antisense RNA 1; ROR: regulator of reprogramming; rRNAs: ribosomal RNAs; SPRY4-IT1: SPRY4 intronic transcript 1; SNHG17: small nucleolar RNA host gene 17; snoRNAs: small nucleolar RNAs; tRNAs: transfer RNAs.
\end{abstract}

\section{Authors' contributions}

MA and SS revised the literature and wrote the paper. $\mathrm{RH}$ and $\mathrm{CJ}$ revised the manuscript. All the authors read and approved the final manuscript.

\begin{abstract}
Author details
${ }^{1}$ Cancer Biology and Epigenetics Group, IPO Porto Research Center (CI-IPOP), Portuguese Oncology Institute of Porto (IPOPorto), Research Center-LAB 3, F Bdg, 1st floor, Rua Dr. António Bernardino de Almeida, 4200-072 Porto, Portugal. ${ }^{2}$ Institute of Biomedical Sciences Abel Salazar, University of Porto (ICBAS-UP), Porto, Portugal. ${ }^{3}$ Department of Pathology, Portuguese Oncology Institute of Porto, Porto, Portugal. ${ }^{4}$ Department of Pathology and Molecular Immunology, Institute of Biomedical Sciences Abel Salazar, University of Porto (ICBAS-UP), Porto, Portugal.
\end{abstract}

\section{Acknowledgements}

Not applicable.

\section{Competing interests}

The authors declare that they have no competing interests.

\section{Funding}

This work was supported by the Research Center of the Portuguese Oncology Institute of Porto.
Received: 30 June 2016 Accepted: 31 August 2016

Published online: 15 September 2016

References

1. Network CGA. Comprehensive molecular portraits of human breast tumours. Nature. 2012;490:61-70.

2. Torre LA, et al. Global cancer statistics, 2012. CA Cancer J Clin. 2015:65:87-108. doi:10.3322/caac.21262.

3. Serpico D, Molino L, Di Cosimo S. microRNAs in breast cancer development and treatment. Cancer Treat Rev. 2014;40:595-604. doi:10.1016/j. ctrv.2013.11.002.

4. Sørlie T. Molecular portraits of breast cancer: tumour subtypes as distinct disease entities. Eur J Cancer. 2004;40:2667-75.

5. Verma A, Kaur J, Mehta K. Molecular oncology update: breast cancer gene expression profiling. Asian J Oncol. 2015;1:65.

6. Fitzgibbons $\mathrm{PL}$, et al. Template for reporting results of biomarker testing of specimens from patients with carcinoma of the breast. Arch Pathol Lab Med. 2014;138:595-601. doi:10.5858/arpa.2013-0566-CP.

7. Hammond ME, et al. American Society of Clinical Oncology/College of American Pathologists guideline recommendations for immunohistochemical testing of estrogen and progesterone receptors in breast cancer (unabridged version). Arch Pathol Lab Med. 2010;134:e48-72. doi:10.1043/1543-2165-134.7.e48.

8. Haque R, et al. Impact of breast cancer subtypes and treatment on survival: an analysis spanning two decades. Cancer Epidemiol Biomark Prev. 2012;21:1848-55. doi:10.1158/1055-9965.EPI-12-0474.

9. Ades F, et al. Luminal B breast cancer: molecular characterization, clinical management, and future perspectives. J Clin Oncol. 2014;32:2794803. doi:10.1200/JCO.2013.54.1870.

10. Blows FM, et al. Subtyping of breast cancer by immunohistochemistry to investigate a relationship between subtype and short and long term survival: a collaborative analysis of data for 10,159 cases from 12 studies. PLoS Med. 2010;7:e1000279.

11. Ciriello G, et al. The molecular diversity of luminal a breast tumors. Breast Cancer Res Treat. 2013;141:409-20. doi:10.1007/ s10549-013-2699-3. 
12. Zhang MH, Man HT, Zhao XD, Dong N, Ma SL. Estrogen receptorpositive breast cancer molecular signatures and therapeutic potentials (review). Biomed Rep. 2014;2:41-52. doi:10.3892/br.2013.187.

13. Györffy B, et al. Multigene prognostic tests in breast cancer: past, present, future. Breast Cancer Res. 2015;17:11.

14. Cheang MC, van de Rijn M, Nielsen TO. Gene expression profiling of breast cancer. Ann Rev Pathol. 2008:3:67-97. doi:10.1146/annurev. pathmechdis.3.121806.151505.

15. Lu J, et al. MicroRNA expression profiles classify human cancers. Nature. 2005:435:834-8. doi:10.1038/nature03702.

16. Mitchell PS, et al. Circulating microRNAs as stable blood-based markers for cancer detection. Proc Natl Acad Sci. 2008;105:10513-8.

17. Xi Y, et al. Systematic analysis of microRNA expression of RNA extracted from fresh frozen and formalin-fixed paraffin-embedded samples. RNA. 2007;13:1668-74

18. Gilad $\mathrm{S}$, et al. Serum microRNAs are promising novel biomarkers. PLoS ONE. 2008;3:e3148.

19. Chen $X$, Liang H, Zhang J, Zen K, Zhang C-Y. Secreted microRNAs: a new form of intercellular communication. Trends Cell Biol. 2012;22:125-32.

20. Palma J, et al. MicroRNAs are exported from malignant cells in customized particles. Nucleic Acids Res. 2012;40:9125-38.

21. Mattick JS, Makunin IV. Non-coding RNA. Hum Mol Genet. 2006;15(1):17-29. doi:10.1093/hmg/ddl046.

22. Sharp SJ, Schaack J, Cooley L, Burke DJ, Soil D. Structure and transcription of eukaryotic tRNA gene. CRC Crit Rev Biochem. 1985;19:107-44.

23. Pavon-Eternod $\mathrm{M}$, et al. tRNA over-expression in breast cancer and functional consequences. Nucleic Acids Res. 2009;37:7268-80. doi:10.1093/nar/gkp787.

24. Pederson T. Regulatory RNAs derived from transfer RNA? RNA. 2010;16:1865-9. doi:10.1261/rna.2266510.

25. Park IH, et al. Identification and clinical implications of circulating microRNAs for estrogen receptor-positive breast cancer. Tumour Biol. 2014:35:12173-80. doi:10.1007/s13277-014-2525-5.

26. Dhahbi JM, Spindler SR, Atamna H, Boffelli D, Martin DI. Deep sequencing of serum small RNAs identifies patterns of 5'tRNA Half and YRNA fragment expression associated with breast cancer. Biomark Cancer. 2014;6:37.

27. Spizzo R, Almeida MI, Colombatti A, Calin GA. Long non-coding RNAs and cancer: a new frontier of translational research\&quest. Oncogene. 2012:31:4577-87.

28. Kung JT, Colognori D, Lee JT. Long noncoding RNAs: past, present, and future. Genetics. 2013;193:651-69. doi:10.1534/genetics.112.146704.

29. Kung JT, Colognori D, Lee JT. Long noncoding RNAs: past, present, and future. Genetics. 2013;193:651-69.

30. Malih S, Saidijam M, Malih N. A brief review on long noncoding RNAs: a new paradigm in breast cancer pathogenesis, diagnosis and therapy. Tumour Biol. 2016;37:1479-85. doi:10.1007/s13277-015-4572-y.

31. Ding $X$, et al. Long intergenic non-coding RNAs (LincRNAs) identified by RNA-seq in breast cancer. PLoS ONE. 2014;9:e103270. doi:10.1371/ journal.pone. 0103270

32. Su X, et al. Comprehensive analysis of long non-coding RNAs in human breast cancer clinical subtypes. Oncotarget. 2014;5:9864-76. doi:10.18632/oncotarget.2454.

33. $\mathrm{Xu} \mathrm{N}$, et al. Clinical significance of high expression of circulating serum IncRNA RP1 1-445H22.4 in breast cancer patients: a Chinese population-based study. Tumour Biol. 2015;36:7659-65. doi:10.1007/ s13277-015-3469-0.

34. Zhao W, Luo J, Jiao S. Comprehensive characterization of cancer subtype associated long non-coding RNAs and their clinical implications. Sci Rep. 2014;4:6591.

35. Shi Y, et al. The long noncoding RNA SPRY4-IT1 increases the proliferation of human breast cancer cells by upregulating ZNF703 expression. Mol Cancer. 2015;14:51. doi:10.1186/s12943-015-0318-0.

36. Gupta RA, et al. Long non-coding RNA HOTAIR reprograms chromatin state to promote cancer metastasis. Nature. 2010;464:1071-6. doi:10.1038/nature08975.

37. Sørensen KP, et al. Long non-coding RNA HOTAIR is an independent prognostic marker of metastasis in estrogen receptor-positive primary breast cancer. Breast Cancer Res Treat. 2013;142:529-36.

38. Arun $\mathrm{G}$, et al. Differentiation of mammary tumors and reduction in metastasis upon Malat1 IncRNA loss. Genes Dev. 2016;30:34-51.
39. Chi Y, et al. Role of BC040587 as a predictor of poor outcome in breast cancer. Cancer Cell Int. 2014;14:1.

40. Hu P, et al. NBAT1 suppresses breast cancer metastasis by regulating DKK1 via PRC2. Oncotarget. 2015;6:32410-25. doi:10.18632/ oncotarget.5609.

41. Xu SP, et al. Downregulation of the long noncoding RNA EGOT correlates with malignant status and poor prognosis in breast cancer. Tumour Biol. 2015;36:9807-12. doi:10.1007/s13277-015-3746-y.

42. Shen $Y$, et al. Prognostic and predictive values of long non-coding RNA LINC00472 in breast cancer. Oncotarget. 2015;6:8579-92. doi:10.18632/ oncotarget.3287.

43. Godinho MF, et al. Relevance of BCAR4 in tamoxifen resistance and tumour aggressiveness of human breast cancer. Br J Cancer. 2010;103:1284-91. doi:10.1038/sj.bjc.6605884.

44. Jonsson $\mathrm{P}$, et al. Single-molecule sequencing reveals estrogenregulated clinically relevant IncRNAs in breast cancer. Mol Endocrinol. 2015;29:1634-45. doi:10.1210/me.2015-1153.

45. Shi SJ, et al. LncRNA-ATB promotes trastuzumab resistance and invasion-metastasis cascade in breast cancer. Oncotarget. 2015;6:1 1652-63. doi:10.18632/oncotarget.3457.

46. Bedrosian JW, Foekens JA, Berindan-Neagoe I, Calin GA. CCAT2, a novel long non-coding RNA in breast cancer: expression study and clinical correlations. 2013

47. Chen YM, Liu Y, Wei HY, Lv KZ, Fu P. Linc-ROR induces epithelial-mesenchymal transition and contributes to drug resistance and invasion of breast cancer cells. Tumour Biol. 2016; doi:10.1007/s13277-016-4909-1.

48. Ruby JG, Jan CH, Bartel DP. Intronic microRNA precursors that bypass Drosha processing. Nature. 2007:448:83-6.

49. Huntzinger E, Izaurralde E. Gene silencing by microRNAs: contributions of translational repression and mRNA decay. Nat Rev Genet. 2011:12:99-110. doi:10.1038/nrg2936.

50. Calin GA, et al. Frequent deletions and down-regulation of micro-RNA genes miR15 and miR16 at 13q14 in chronic lymphocytic leukemia. Proc Natl Acad Sci. 2002;99:15524-9.

51. Bertoli G, Cava C, Castiglioni I. microRNAs: new biomarkers for diagnosis, prognosis, therapy prediction and therapeutic tools for breast cancer. Theranostics. 2015;5:1122-43. doi:10.7150/thno.11543.

52. Goh JN, et al. microRNAs in breast cancer: regulatory roles governing the hallmarks of cancer. Biol Rev Camb Philos Soc. 2016;91:409-28. doi:10.1111/brv.12176.

53. Keklikoglou I, et al. MicroRNA-520/373 family functions as a tumor suppressor in estrogen receptor negative breast cancer by targeting NF-KB and TGF- $\beta$ signaling pathways. Oncogene. 2012;31:4150-63.

54. Sempere LF, et al. Altered MicroRNA expression confined to specific epithelial cell subpopulations in breast cancer. Cancer Res. 2007;67:1161220. doi:10.1158/0008-5472.CAN-07-5019.

55. Ma L, Teruya-Feldstein J, Weinberg RA. Tumour invasion and metastasis initiated by microRNA-10b in breast cancer. Nature. 2007:449:682-8. doi:10.1038/nature06174.

56. Volinia $\mathrm{S}$, et al. Breast cancer signatures for invasiveness and prognosis defined by deep sequencing of microRNA. Proc Natl Acad Sci USA. 2012;109:3024-9. doi:10.1073/pnas.1200010109.

57. Iorio MV, et al. microRNA gene expression deregulation in human breast cancer. Cancer Res. 2005;65:7065-70. doi:10.1158/0008-5472.CAN-05-1783.

58. Heneghan $\mathrm{HM}$, et al. Circulating microRNAs as novel minimally invasive biomarkers for breast cancer. Ann Surg. 2010;251:499-505.

59. Wu Q, Wang C, Lu Z, Guo L, Ge Q. Analysis of serum genome-wide microRNAs for breast cancer detection. Clin Chim Acta. 2012;413:105865. doi:10.1016/j.cca.2012.02.016.

60. Zhang H, Li B, Zhao H, Chang J. The expression and clinical significance of serum miR-205 for breast cancer and its role in detection of human cancers. Int J Clin Exp Med. 2015;8:3034-43.

61. Zhao F-L, et al. Serum microRNA-195 is down-regulated in breast cancer: a potential marker for the diagnosis of breast cancer. Mol Biol Rep. 2014;41:5913-22.

62. Hu Z, et al. Serum microRNA profiling and breast cancer risk: the use of miR-484/191 as endogenous controls. Carcinogenesis. 2012;33(4):828-34.

63. Zhang $L$, et al. A circulating miRNA signature as a diagnostic biomarker for non-invasive early detection of breast cancer. Breast Cancer Res Treat. 2015;154:423-34. 
64. Ng EK, et al. Circulating microRNAs as specific biomarkers for breast cancer detection. PLoS ONE. 2013;8:e53141.

65. Cuk K, et al. Plasma microRNA panel for minimally invasive detection of breast cancer. PLoS ONE. 2013;8:e76729. doi:10.1371/journal. pone.0076729.

66. Eissa S, Matboli M, Shehata HH. Breast tissue-based microRNA panel highlights microRNA-23a and selected target genes as putative biomarkers for breast cancer. Transl Res. 2015;165:417-27.

67. Hui $A B$, et al. Robust global micro-RNA profiling with formalin-fixed paraffin-embedded breast cancer tissues. Lab Invest. 2009;89:597-606. doi:10.1038/labinvest.2009.12.

68. Krishnan $P$, et al. Next generation sequencing profiling identifies miR-574-3p and miR-660-5p as potential novel prognostic markers for breast cancer. BMC Genom. 2015;16:1.

69. Mar-Aguilar F, et al. Serum circulating microRNA profiling for identification of potential breast cancer biomarkers. Dis Markers. 2013;34:163-9. doi:10.3233/DMA-120957.

70. Chan $\mathrm{M}$, et al. Identification of circulating microRNA signatures for breast cancer detection. Clin Cancer Res. 2013;19:4477-87. doi:10.1158/1078-0432.CCR-12-3401.

71. Antolin S, et al. Circulating miR-200c and miR-141 and outcomes in patients with breast cancer. BMC Cancer. 2015;15:297. doi:10.1186/ s12885-015-1238-5.

72. Frères $P$, et al. Circulating microRNA-based screening tool for breast cancer. Oncotarget. 2016;7(5):5416-28.

73. Matamala N, et al. Tumor microRNA expression profiling identifies circulating microRNAs for early breast cancer detection. Clin Chem. 2015;61:1098-106. doi:10.1373/clinchem.2015.238691.

74. Lowery AJ, et al. MicroRNA signatures predict oestrogen receptor, progesterone receptor and HER2/neu receptor status in breast cancer. Breast Cancer Res. 2009;11:R27. doi:10.1186/bcr2257.

75. Cizeron-Clairac G, et al. MiR-190b, the highest up-regulated miRNA in ERa-positive compared to ERa-negative breast tumors, a new biomarker in breast cancers? BMC Cancer. 2015;15:499.

76. He YJ, et al. miR-342 is associated with estrogen receptor-a expression and response to tamoxifen in breast cancer. Exp Ther Med. 2013;5:813-8.

77. Wang PY, et al. Higher expression of circulating miR-182 as a novel biomarker for breast cancer. Oncol Lett. 2013;6:1681-6.

78. Wu X, et al. De novo sequencing of circulating miRNAs identifies novel markers predicting clinical outcome of locally advanced breast cancer. J Transl Med. 2012;10:42. doi:10.1186/1479-5876-10-42.

79. Zhu W, Qin W, Atasoy U, Sauter ER. Circulating microRNAs in breast cancer and healthy subjects. BMC Res Notes. 2009;2:89. doi:10.1186/1756-0500-2-89.

80. Tashkandi H, Shah N, Patel Y, Chen H. Identification of new miRNA biomarkers associated with HER2-positive breast cancers. Oncoscience. 2015;2:924-9.

81. Blenkiron C, et al. MicroRNA expression profiling of human breast cancer identifies new markers of tumor subtype. Genome Biol. 2007;8:R214. doi:10.1186/gb-2007-8-10-r214.

82. Endo $Y$, et al. miR-1290 and its potential targets are associated with characteristics of estrogen receptor alpha-positive breast cancer. Endocr Relat Cancer. 2013:20:91-102. doi:10.1530/ERC-12-0207.

83. Iorio MV, Casalini P, Tagliabue E, Ménard S, Croce CM. MicroRNA profiling as a tool to understand prognosis, therapy response and resistance in breast cancer. Eur J Cancer. 2008;44:2753-9.

84. Shell S, et al. Let-7 expression defines two differentiation stages of cancer. Proc Natl Acad Sci USA. 2007;104:11400-5. doi:10.1073/ pnas.0704372104.

85. Jemal A, Siegel R, XU J, Ward E. Cancer statistics, 2010. CA Cancer J Clin. 2010;60:277-300. doi:10.3322/caac.20073.

86. Madhavan D, et al. Circulating miRNAs as surrogate markers for circulating tumor cells and prognostic markers in metastatic breast cancer. Clin Cancer Res. 2012;18:5972-82.

87. Ma L, et al. miR-9, a MYC/MYCN-activated microRNA, regulates E-cadherin and cancer metastasis. Nat Cell Biol. 2010;12:247-56. doi:10.1038/ ncb2024.

88. Chen W, Cai F, Zhang B, Barekati Z, Zhong XY. The level of circulating miRNA-10b and miRNA-373 in detecting lymph node metastasis of breast cancer: potential biomarkers. Tumour Biol. 2013;34:455-62. doi:10.1007/s13277-012-0570-5.
89. Song B, et al. MicroRNA-21 regulates breast cancer invasion partly by targeting tissue inhibitor of metalloproteinase 3 expression. J Exp Clin Cancer Res. 2010;29:29. doi:10.1186/1756-9966-29-29.

90. Gebeshuber CA, Zatloukal K, Martinez J. miR-29a suppresses tristetraprolin, which is a regulator of epithelial polarity and metastasis. EMBO Rep. 2009;10:400-5.

91. Petrović $\mathrm{N}$, et al. miR-155 expression level changes might be associated with initial phases of breast cancer pathogenesis and lymph-node metastasis. Cancer Biomarkers. 2016;16:385-94.

92. Huang Q, et al. The microRNAs miR-373 and miR-520c promote tumour invasion and metastasis. Nat Cell Biol. 2008:10:202-10. doi:10.1038/ncb1681.

93. Schwarzenbach H, Milde-Langosch K, Steinbach B, Muller V, Pantel K. Diagnostic potential of PTEN-targeting miR-214 in the blood of breast cancer patients. Breast Cancer Res Treat. 2012;134:933-41. doi:10.1007/ s10549-012-1988-6.

94. Shi W, et al. MicroRNA-301 mediates proliferation and invasion in human breast cancer. Cancer Res. 2011;71:2926-37. doi:10.1158/00085472. CAN-10-3369.

95. ZhanY, et al. microRNA-548j functions as a metastasis promoter in human breast cancer by targeting tensin 1 . Molecular Oncology. 2016;10(6):838-49.

96. Yu Z, et al. microRNA 17/20 inhibits cellular invasion and tumor metastasis in breast cancer by heterotypic signaling. Proc Natl Acad Sci USA. 2010;107:8231-6. doi:10.1073/pnas.1002080107.

97. Png KJ, Halberg N, Yoshida M, Tavazoie SF. A microRNA regulon that mediates endothelial recruitment and metastasis by cancer cells. Nature. 2012:481:190-4. doi:10.1038/nature10661.

98. Li XF, Yan PJ, Shao ZM. Downregulation of miR-193b contributes to enhance urokinase-type plasminogen activator (UPA) expression and tumor progression and invasion in human breast cancer. Oncogene. 2009;28:3937-48. doi:10.1038/onc.2009.245.

99. Song G, Zhang Y, Wang L. MicroRNA-206 targets notch3, activates apoptosis, and inhibits tumor cell migration and focus formation. J Biol Chem. 2009;284:31921-7. doi:10.1074/jbc.M109.046862.

100. Tavazoie SF, et al. Endogenous human microRNAs that suppress breast cancer metastasis. Nature. 2008;451:147-52.

101. Li Q, et al. Involvement of NF-KB/miR-448 regulatory feedback loop in chemotherapy-induced epithelial-mesenchymal transition of breast cancer cells. Cell Death Differ. 2011;18:16-25.

102. Hu J-Y, et al. miR-601 is a prognostic marker and suppresses cell growth and invasion by targeting PTP4A1 in breast cancer. Biomed Pharmacother. 2016;79:247-53.

103. Zhang $J$, et al. MicroRNA-138 modulates metastasis and EMT in breast cancer cells by targeting vimentin. Biomed Pharmacother. 2016;77:13541. doi:10.1016/j.biopha.2015.12.018.

104. Pardo OE, et al. miR-515-5p controls cancer cell migration through MARK4 regulation. EMBO Rep. 2016;17(4):570-84.

105. Zhao S, et al. MicroRNA-203 Regulates Growth and Metastasis of Breast Cancer. Cell Physiol Biochem. 2015;37:35-42. doi:10.1159/000430331.

106. Gregory PA, et al. The miR-200 family and miR-205 regulate epithelial to mesenchymal transition by targeting ZEB1 and SIP1. Nat Cell Biol. 2008;10:593-601. doi:10.1038/ncb1722.

107. Yan L-X, et al. MicroRNA miR-21 overexpression in human breast cancer is associated with advanced clinical stage, lymph node metastasis and patient poor prognosis. RNA. 2008;14:2348-60.

108. Markou A, Yousef GM, Stathopoulos E, Georgoulias V, Lianidou E. Prognostic significance of metastasis-related microRNAs in early breast cancer patients with a long follow-up. Clin Chem. 2014;60:197-205. doi:10.1373/clinchem.2013.210542.

109. Camps C, et al. hsa-miR-210 Is induced by hypoxia and is an independent prognostic factor in breast cancer. Clin Cancer Res. 2008;14:1340-8.

110. Rothe F, et al. Global microRNA expression profiling identifies MiR-210 associated with tumor proliferation, invasion and poor clinical outcome in breast cancer. PLoS ONE. 2011;6:e20980. doi:10.1371/journal. pone.0020980.

111. Cheng C-W, et al. MicroRNA-30a inhibits cell migration and invasion by downregulating vimentin expression and is a potential prognostic marker in breast cancer. Breast Cancer Res Treat. 2012;134:1081-93.

112. Zhang N, et al. MicroRNA-30a suppresses breast tumor growth and metastasis by targeting metadherin. Oncogene. 2014;33:3119-28. doi:10.1038/onc.2013.286. 
113. D'Aiuto F, et al. miR-30e* is an independent subtype-specific prognostic marker in breast cancer. Br J Cancer. 2015;113:290-8.

114. Shimono Y, et al. Downregulation of miRNA-200c links breast cancer stem cells with normal stem cells. Cell. 2009;138:592-603. doi:10.1016/j. cell.2009.07.011.

115. Liu S, Wicha MS. Targeting breast cancer stem cells. J Clin Oncol. 2010;28:4006-12. doi:10.1200/JCO.2009.27.5388.

116. Bailey ST, Westerling T, Brown M. Loss of estrogen-regulated microRNA expression increases HER2 signaling and is prognostic of poor outcome in luminal breast cancer. Cancer Res. 2015;75:436-45.

117. Gasparini P, et al. microRNA expression profiling identifies a four microRNA signature as a novel diagnostic and prognostic biomarker in triple negative breast cancers. Oncotarget. 2014;5:1174-84.

118. Tuomarila M, et al. Overexpression of microRNA-200c predicts poor outcome in patients with PR-negative breast cancer. PLOS ONE. 2014;9:e109508. doi:10.1371/journal.pone.0109508.

119. Zhang $B$, et al. microRNA 100 sensitizes luminal a breast cancer cells to paclitaxel treatment in part by targeting MTOR. Oncotarget. 2016;7(5):5702-14.

120. Peng $F$, et al. Identification of differentially expressed miRNAs in individual breast cancer patient and application in personalized medicine. Oncogenesis. 2016:5:e194. doi:10.1038/oncsis.2016.4.

121. Zhu Y, et al. Reduced miR-128 in breast tumor-initiating cells induces chemotherapeutic resistance via Bmi-1 and ABCC5. Clin Cancer Res. 2011;17:7105-15. doi:10.1158/1078-0432.CCR-11-0071.

122. Quesne $\mathrm{JL}$, et al. Biological and prognostic associations of miR-205 and let-7b in breast cancer revealed by in situ hybridization analysis of micro-RNA expression in arrays of archival tumour tissue. J Pathol. 2012:227:306-14. doi:10.1002/path.3983.

123. Leivonen SK, et al. High-throughput screens identify microRNAs essential for HER2 positive breast cancer cell growth. Mol Oncol. 2014;8:93104. doi:10.1016/j.molonc.2013.10.001

124. Shen $\mathrm{L}$, et al. miR-497 induces apoptosis of breast cancer cells by targeting Bcl-w. Exp Ther Med. 2012;3:475-80. doi:10.3892/etm.2011.428.

125. Wu ZS, et al. Loss of miR-133a expression associated with poor survival of breast cancer and restoration of miR-133a expression inhibited breast cancer cell growth and invasion. BMC Cancer. 2012;12:51. doi:10.1186/1471-2407-12-51.

126. Li Y, Hong F, Yu Z. Decreased expression of microRNA-206 in breast cancer and its association with disease characteristics and patient survival. J Int Med Res. 2013;41:596-602. doi:10.1177/0300060513485856.

127. Dong L-L, Chen L-M, Wang W-M, Zhang L-M. Decreased expression of microRNA-124 is an independent unfavorable prognostic factor for patients with breast cancer. Diag Pathol. 2015;10:45.

128. Xu F, et al. Decreased expression of MicroRNA-200 family in human breast cancer is associated with lymph node metastasis. Clin Transl Oncol. 2016;18(3):1-6.

129. Shinden $\mathrm{Y}$, et al. miR-29b is an indicator of prognosis in breast cancer patients. Mol Clin Oncol. 2015;3:919-23.

130. Tang W, et al. MiR-27 as a prognostic marker for breast cancer progression and patient survival. PLoS ONE. 2012;7:e51702.

131. Shen R, et al. MiRNA-155 mediates TAM resistance by modulating SOCS6-STAT3 signalling pathway in breast cancer. Am J Transl Res. 2015; 7:2115-26.

132. Farazi $T A$, et al. MicroRNA sequence and expression analysis in breast tumors by deep sequencing. Cancer Res. 2011;71:4443-53. doi:10.1158/0008-5472.CAN-11-0608.

133. Mulrane $L$, et al. miR-187 is an independent prognostic factor in breast cancer and confers increased invasive potential in vitro. Clin Cancer Res. 2012;18:6702-13.

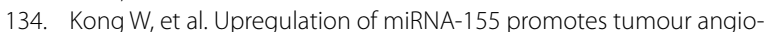
genesis by targeting $\mathrm{VHL}$ and is associated with poor prognosis and triple-negative breast cancer. Oncogene. 2014;33:679-89.

135. Falkenberg N, et al. MiR-221/-222 differentiate prognostic groups in advanced breast cancers and influence cell invasion. Br J Cancer. 2013:109:2714-23. doi:10.1038/bjc.2013.625.

136. Lerebours F, et al. miRNA expression profiling of inflammatory breast cancer identifies a 5-miRNA signature predictive of breast tumor aggressiveness. Int J Cancer. 2013;133:1614-23. doi:1 0.1002/ijc.28171.

137. Zehentmayr $\mathrm{F}$, et al. Hsa-miR-375 is a predictor of local control in early stage breast cancer. Clin Epigen. 2016;8:1.
138. Shen S, et al. A prognostic model of triple-negative breast cancer based on miR-27b-3p and node status. PLoS ONE. 2014;9:e100664. doi:10.1371/journal.pone.0100664.

139. Hu J, et al. Identification of microRNA-93 as a functional dysregulated miRNA in triple-negative breast cancer. Tumor Biol. 2015;36:251-8.

140. Singh R, Mo YY. Role of microRNAs in breast cancer. Cancer Biol Ther. 2013;14:201-12. doi:10.4161/cbt.23296.

141. Svoboda M, et al. MiR-34b is associated with clinical outcome in triplenegative breast cancer patients. Diagn Pathol. 2012;7:31.

142. Sahlberg KK, et al. A serum microRNA signature predicts tumor relapse and survival in triple-negative breast cancer patients. Clin Cancer Res. 2015;21:1207-14

143. Joosse SA, Muller V, Steinbach B, Pantel K, Schwarzenbach H. Circulating cell-free cancer-testis MAGE-A RNA, BORIS RNA, let-7b and miR-202 in the blood of patients with breast cancer and benign breast diseases. $\mathrm{Br}$ J Cancer. 2014;111:909-17. doi:10.1038/bjc.2014.360.

144. Mangolini A, et al. Diagnostic and prognostic microRNAs in the serum of breast cancer patients measured by droplet digital PCR. Biomark Res. 2015;3:12. doi:10.1186/s40364-015-0037-0.

145. Roth C, et al. Circulating microRNAs as blood-based markers for patients with primary and metastatic breast cancer. Breast Cancer Res. 2010:12:R90.

146. Maillot $\mathrm{G}$, et al. Widespread estrogen-dependent repression of microRNAs involved in breast tumor cell growth. Cancer Res. 2009;69:8332-40. doi:10.1158/0008-5472.CAN-09-2206.

147. Rodríguez-González FG, et al. MicroRNA-30c expression level is an independent predictor of clinical benefit of endocrine therapy in advanced estrogen receptor positive breast cancer. Breast Cancer Res Treat. 2011;127:43-51.

148. Jung EJ, et al. Plasma microRNA 210 levels correlate with sensitivity to trastuzumab and tumor presence in breast cancer patients. Cancer. 2012;118:2603-14. doi:10.1002/cncr.26565.

149. Cittelly DM, et al. Downregulation of miR-342 is associated with tamoxifen resistant breast tumors. Mol Cancer. 2010;9:1.

150. Jansen MP, et al. High miR-26a and low CDC2 levels associate with decreased EZH2 expression and with favorable outcome on tamoxifen in metastatic breast cancer. Breast Cancer Res Treat. 2012;133:937-47. doi:10.1007/s10549-011-1877-4.

151. Hoppe R, et al. Increased expression of miR-126 and miR-10a predict prolonged relapse-free time of primary oestrogen receptorpositive breast cancer following tamoxifen treatment. Eur J Cancer. 2013:49:3598-608. doi:10.1016/j.ejca.2013.07.145.

152. Miller TE, et al. MicroRNA-221/222 confers tamoxifen resistance in breast cancer by targeting p27Kip1. J Biol Chem. 2008:283:29897-903. doi:10.1074/jbc.M804612200.

153. Rao X, et al. MicroRNA-221/222 confers breast cancer fulvestrant resistance by regulating multiple signaling pathways. Oncogene. 2011:30:1082-97. doi:10.1038/onc.2010.487.

154. Ward A, et al. MicroRNA-519a is a novel oncomir conferring tamoxifen resistance by targeting a network of tumour-suppressor genes in ER + breast cancer. J Pathol. 2014;233:368-79.

155. Kazi AA, et al. HER2 regulated miRNA expression in letrozole resistant breast cancer. Cancer Res. 2014;74:1471-2.

156. Gong C, et al. Up-regulation of miR-21 mediates resistance to trastuzumab therapy for breast cancer. J Biol Chem. 2011;286:19127-37. doi:10.1074/jbc.M110.216887.

157. Kovalchuk $\mathrm{O}$, et al. Involvement of microRNA-451 in resistance of the MCF-7 breast cancer cells to chemotherapeutic drug doxorubicin. Mol Cancer Ther. 2008:7:2152-9. doi:10.1158/1535-7163.MCT-08-0021.

158. Chen J, Tian W, Cai H, He H, Deng Y. Down-regulation of microRNA-200C is associated with drug resistance in human breast cancer. Med Oncol. 2012:29:2527-34.

159. Lu L, Ju F, Zhao H, Ma X. MicroRNA-134 modulates resistance to doxorubicin in human breast cancer cells by downregulating ABCC1. Biotechnol Lett. 2015;37:2387-94. doi:10.1007/s10529-015-1941-y.

160. Tang $X$, et al. MicroRNA-16 sensitizes breast cancer cells to paclitaxel through suppression of IKBKB expression. Oncotarget. 2016; doi:10.18632/oncotarget.8056.

161. Xue J, et al. MiRNA-621 sensitizes breast cancer to chemotherapy by suppressing FBXO11 and enhancing p53 activity. Oncogene. 2016;35:448-58. doi:10.1038/onc.2015.96. 
162. Wang $\mathrm{H}$, et al. Circulating MiR-125b as a marker predicting chemoresistance in breast cancer. PLOS ONE. 2012;7:e34210.

163. Zheng $Y$, et al. A microRNA expression signature in taxane-anthracycline-based neoadjuvant chemotherapy response. J Cancer. 2015;6:671-7. doi:10.7150/jca.11616.

164. Zhao R, et al. Plasma miR-221 as a predictive biomarker for chemoresistance in breast cancer patients who previously received neoadjuvant chemotherapy. Oncol Res Treat. 2011;34:675-80.
165. Kong W, et al. MicroRNA-155 regulates cell survival, growth, and chemosensitivity by targeting FOXO3a in breast cancer. J Biol Chem. 2010;285:17869-79. doi:10.1074/jbc.M110.101055.

166. Gasparini P, et al. Protective role of miR-155 in breast cancer through RAD51 targeting impairs homologous recombination after irradiation. Proc Natl Acad Sci. 2014;111:4536-41.

\section{Submit your next manuscript to BioMed Central and we will help you at every step:}

- We accept pre-submission inquiries

- Our selector tool helps you to find the most relevant journal

- We provide round the clock customer support

- Convenient online submission

- Thorough peer review

- Inclusion in PubMed and all major indexing services

- Maximum visibility for your research

Submit your manuscript at

www.biomedcentral com/submit 